\title{
Capillary Electrophoresis of Single-stranded DNA
}

\author{
Hyunju Choi and Yongseong Kim* \\ Division of Chemistrv and Chemical Engineering, Kvingnam Chiversity. Masan 631-701, Korea \\ Received Febriary +, 2003
}

\begin{abstract}
We have studied the migration behavior of single-stranded DNA using capillary gel electrophoresis under various conditions. It was found that optimum electric fields should be less than $150 \mathrm{~V} / \mathrm{cm}$ for the good tradeoff between the separation time and the resolution. It seems that the gel matrix with the combination of different polymer average molecular weights is important to extend the maximum readable DNA bases. The total gel concentration less than $3.1 \%$ in the mixed gel system showed good separation efficiency up to 600 bases. The best result was obtained with the poy (ethylene)oxide (PEO) gel concentration of $1.2 \%$ of $\mathrm{Mr} 8.000 .000$ and $1.8 \%$ of $\mathrm{Mr} 600.000$. We observed that the capillary length between $50 \mathrm{~cm}$ to $100 \mathrm{~cm}$ (effective length) should be employed for the optimization between the total DNA migration time and the maximum readable length. A trizma base-boric acid-ethlyenediaminetetraacetic acid (EDTA) (TBE) buffer was commonly used for DNA sequencing. but we found that 3-[tris(hydroxỵmethỵl)methyl amino]-l-propane sulfonic acid (TAPS) buffer worked as well for the single-stranded DNA separation. Especially. TAPS buffer showed a good resolution for very short DNA bases ( 1 to 30 bases)
\end{abstract}

Key Words : Capillary electrophoresis, DNA. Sequencing. Huntan Genome Project (HGP)

\section{Introduction}

Rapid and efficient separation of single-stranded DNA has been the key issue in the era of Human Genome Project. ${ }^{1.3}$ Although post-Genome projects are focused more on proteins and drug development. ${ }^{4.6}$ DNA separation is still important in the research area of biochemistry, molecular biology, and medicinal chemistry. ${ }^{7}$ For example. single nucleotide polymorphism (SNP) is known to be the main source of genetic diseases $^{s}$ and SNP analysis requires DNA sequencing with one-base resolution. In forensic analysis, the analysis of DNA fragments with four- to five-base resolution in tandem DNA repeats has been studied. 9.11

Slab gel electrophoresis has been the method of choice for DNA fragment analysis. Low-cost and easy-operation made it feasible for routine analysis in many research laboratories. However. there are many drawbacks such as gel deformation under high electric field low sensitivity long analysis time. and low resolution. " After capillary electrophoresis (CE) was introduced in scientific society around mid-1980. it was greatly employed for the study of biomolecules due to high sensitivity high resolution. short analysis time and automation capability: ${ }^{1 \pm-14}$

Depending on the mode of separation. there are many ways to be called in capillary electrophoresis. capillary zone electrophoresis (CZE), capillary isoelectric focusing (CIEF). micellar electrokinetic chromatography (MEKC) and capillary gel electrophoresis (CGE). For DNA separation. the discrimination of DNA according to its size is needed since in the view of polymer. DNA is simply polyanion. Among several modes of separation. CGE has been extensively employed since the gel matrix provides the capability of sieving for different sizes of DNA fragments. ${ }^{15}$

CGE has been extensively employed for the study of DNA sequencing. ${ }^{16}$ DNA restriction fragment analysis, ${ }^{17}$ and polymerase chain reaction (PCR) fragment analysis. ${ }^{18}$ In CGE, one- or four-base resolution was easily obtained by the proper choice of gel matrix and concentration.

The characteristics of double-stranded (ds) DNA in CGE were well investigated as ds DNA is thought to have the persistence length of about 50 base pair (bp). The Rose chain model has been used for the explanation of migration behavior of ds DNA in CGE with the sieving mechanism of Ogston, reptation. and biased reptation depending on the length of ds DNA. ${ }^{19}$ However. single-stranded DNA, which is the main target in DNA sequencing and SNP analysis. does not provide any sy stematic model since single-stranded DNA is a lot more flexible than ds DNA. Therefore. there is no persistent segment in DNA and its molecular behavior is quite different from that of ds DNA. The study of the migration behavior of single-stranded DNA under various conditions in CGE would be important for DNA sequencing and SNP analỳsis.

Conventionally, a cross-linked polyacrylamide gel has been employed especially in slab gel electrophoresis. However. the problems associated with bubble formation. gel inhomogeneity and the short lifetime of the gel matrix made it less feasible in CGE. Water-soluble polymers including linear polyacryalmide. ${ }^{20}$ cellulose derivatives. ${ }^{21}$ and polyvinyl pyrolydone (PVP) ${ }^{2}$ has been introduced as the sieving matrices inside the capillary. They provide the transient network for a size-dependent separation for the separation of DNA fragments. A very flexible polymer. polyethylene oxide (PEO), showed several advantages over those polymers since it is commercially available. produces very homogeneous solution. and has well-defined relative molecular weights. $^{23}$

We have investigated characteristics of single-stranded 
DNA under different conditions in DNA sequencing. The migration behavior of single-stranded DNA using polyethylene oxide solution as sieving matrix is addressed in this paper.

\section{Experimental Section}

Chemicals. Bare fused silica capillaries with $75 \mu \mathrm{m}$ i.d. and $375 \mathrm{~m}$ o.d. were purchased from Polymicro Technologies. LLC (AZ. USA). A detection window was prepared by burning the polyimide coating with a hot sulfuric acid. Urea was obtained from Sigma Chemical Co. (MO. USA) Formamide for DNA denaturation was from also Sigma Chemical. Tris base boric acid acetic acid. 3-[tris(hydroxymethyl)methyl amino]-l-propane sulfonic acid (TAPS) and EDTA (all from Aldrich. WI. USA) were used for TBE or TAPS buffer preparation. Deionzed water was used for this experiment. Polyethylene oxide (PEO) with Mr 8.000.000 and 600. 000 were from Aldrich. PGEM/U DNA was prepared by cycle sequencing with AmpliTaq FS polymerase. and terminator labeling with standard $\mathrm{ABI}$ reagents.

Capillary electrophoresis. The nun buffer was prepared by dissolving $3.5 \mathrm{M}$ urea in $\mathrm{IX}$ TBE solution $(90 \mathrm{mM}$ Tris. $90 \mathrm{mM}$ borate. and $2 \mathrm{mM}$ EDTA) or TAPS (90mM TAPS and $2 \mathrm{mM}$ EDTA) solution. The buffer was filtered once with $2 \mu \mathrm{m}$ filter paper (Milipore Corp. MA. USA). The polymer gel was prepared by gradually adding PEO with desired concentration of $\mathrm{Mr} 8000000$ and 600000 in $20 \mathrm{~mL}$ of the buffer at room temperature. After addition. the polymer gel was stirred for more than $12 \mathrm{~h}$. then the resulting gel was degassed by vacuum.

A high-voltage power supply (Spellman. NY. USA) was used for electrophoresis. A $1.0 \mathrm{~mW}$ He-Ne laser (Edmund Scientific Co. NJ. USA) with $543.6 \mathrm{~nm}$ output was used for the excitation of DNA labeled dye. Two RG610 optical filters were used to block scattered laser light. The fluorescence signal was transferred directly through a low-pass filter to an A/D interface board (LabView. National instruments Co. TX. USA) and stored in an IBM compatible computer at 5 $\mathrm{Hz}$.

Bare capillaries were cut with effective lengths of 25.50 . 70 . and $100 \mathrm{~cm}$. The capillary was flushed with $5.0 \mathrm{mM} \mathrm{HCl}$ solution for $0.5 \mathrm{~h}$ before PEO gel was introduced. The selected PEO gel was pushed into the capillary with high pressure (more than $6500 \mathrm{~Pa}$ ) for $20-40 \mathrm{~min}$. Two glass vials containing TBE or TAPS buffer $(\mathrm{pH} 8.2)$ with $3.5 \mathrm{M}$ urea was placed on both ends of the capillary. The capillary was electrophoretically equilibrated for $10 \mathrm{~min}$ before sample injection. The DNA sample was denatured by heating in a denaturing solution (formamide: $20 \mathrm{mM} \mathrm{EDTA}=5: 1$ ) at $95^{\circ} \mathrm{C}$ for $3 \mathrm{~min}$. Injection was performed at $150 \mathrm{~V} / \mathrm{cm}$ for $20-25 \mathrm{~s}$. After each nun. the capillary was flushed with 5.0 $\mathrm{mM} \mathrm{HCl}$ solution for $15-30 \mathrm{~min}$, and then a new PEO gel was introduced with the high pressure. For each nun. it was found that the reproducibility for the mobility shift of each DNA base peak was within $2 \%$

The number of theoretical plates $(\mathrm{N})$ and the resolution
(R) were calculated according to the following equations

$\mathrm{N}=5.54(\mathrm{t}(\mathrm{W} / 2))^{2}$

$t:$ migration time of the peak(s)

(W/2) : temporal peak width at half of the peak height(s)

$R=\sqrt{\frac{N}{4}} \cdot \frac{\Delta V}{\bar{V}}$

$\Delta V:$ difference of the migration velocity of two peaks $(\mathrm{cm} / \mathrm{s})$

$\bar{V}:$ mean of migration velocity of two peaks (cm/s)

\section{Results and Discussion}

Figure 1 shows the single-stranded DNA separation of PGEM/U standard sample by CGE after cycle sequencing reaction. The peaks shown in Figure 1 represent DNA bases labeled with fluorescent dyes called carboxyfluorescein (FAM). 6-carboxy -4'5'-dichloro-2' (JOE). carboxytetramethylrhodamine (TAMRA), and carboxy-X-rhodamine (ROX). which are attached to DNA bases of guanine $(\mathrm{G})$. adenine (A), thymine (T), and cytosine (C). respectively. Since the excitation maxima of fluorescent dy'es are different (FAM: $518 \mathrm{~nm}$. JOE: $548 \mathrm{~nm}$. TAMRA: $568 \mathrm{~nm}$. ROX: $602 \mathrm{~nm}$ ). relatively different peak heights make it possible to identify
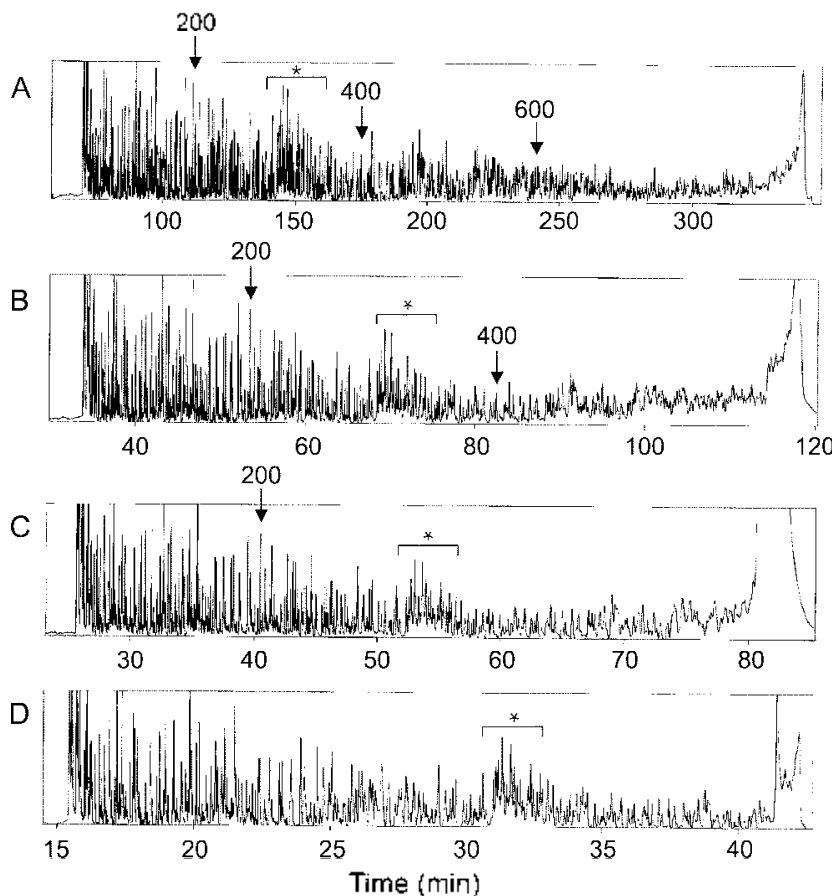

Figure 1. A single-stranded DNA separation of PGEM/U standard sample at various electric fields. (A) $75 \mathrm{~V} / \mathrm{cm}$, (B) $150 \mathrm{~V} / \mathrm{cm}$, (C) $200 \mathrm{~V} / \mathrm{cm}^{\text {s }}$ (D) $300 \mathrm{~V} / \mathrm{cm}$. A total capillary length was $85 \mathrm{~cm}$ with the effective length of $70 \mathrm{~cm}$. Gel matrix was consisted of $1.5 \% \mathrm{Mr}$ $8,000,000$ and $1.4 \% \mathrm{Mr} 600,000$ of poly(ethylene oxide). The butfer was $1 X$ TBE solution $(90 \mathrm{mM}$ Tris, $90 \mathrm{mM}$ borate, and 2 $\mathrm{mM}$ EDTA) containing $3.5 \mathrm{M}$ urea. The DNA sample was denatured by heating in a denaturing solution (formamide: $20 \mathrm{mM}$ $\mathrm{EDTA}=5: 1$ ) at $95^{\circ} \mathrm{C}$ for $3 \mathrm{~min}$. Injection was performed at 150 V/cm for $20-25 \mathrm{~s}$. The numbers represents the DNA bases and *denotes the $G, C$ rich region in PGEM/U DNA primary sequence. 
DNA bases. For example. the higher peaks correspond to DNA base of cytosine since the RG610 cut-off optical filter was employed in front of photomultiplier. However peak identification was not seriously performed in this study because the purpose of this work was to investigate the characteristics of single-stranded DNA migration behavior under high electric fields

When $75 \mathrm{~V} / \mathrm{cm}$ was used. DNA bases more than 600 could be separated with the resolution of around 1.2 (Figure 1A). As the electric field strength increased a total migration time reduced very rapidly and the resolution became deteriorated. resulting in the decrease of DNA length for identification. Higher electric field gave rise to the short analy sis time at the expense of poor separation efficiency. We found that the electric field strength less than $150 \mathrm{~V} / \mathrm{cm}$ should be employed for the good trade-off between the separation time and the resolution

An interesting fact was that the reduction of the total migration time was not simply proportional to the increase of the electric field. For instance. when the field strength changed from $75 \mathrm{~V} / \mathrm{cm}$ to $150 \mathrm{~V} / \mathrm{cm}$ (Figure 1B), the total migration time was $330 \mathrm{~min}$ and $125 \mathrm{~min}$. respectively. Also. the change of electric field strength from $150 \mathrm{~V} / \mathrm{cm}$ to 300 $\mathrm{V} / \mathrm{cm}$ (Figure lD), the total migration time at $300 \mathrm{~V} / \mathrm{cm}$ was about $43 \mathrm{~min}$. This rapid reduction of the total migration time could be attributed the elevation of temperature inside the capillary due to Joule heating caused by Ohm's law. ${ }^{-4}$ The viscosity of the polyethylene oxide gel matrix would be decreased. rendering fast migration of DNA strands.

Another interesting fact was that the resolution depended on the primary structure of DNA bases. When guanine $(\mathrm{G})$ and cytosine $(\mathrm{C})$ became rich in the DNA sequence. the resolution became worse as shown in Figure 1 (marked by *). In PGEM/U sample, this region contains more than $80 \%$ of $\mathrm{G} . \mathrm{C}$ bases. It is known that higher content of $\mathrm{G} . \mathrm{C}$ in specific region of DNA sequence makes it possible to form a loop structure. resulting in poor separation. ${ }^{17}$ The study for the improved resolution in $\mathrm{G} . \mathrm{C}$ rich region is under progress.

Figure 2 shows the electropherograms under three different concentrations of gel matrix. It was known that a mixed gel system with high and low average molecular weight of polymer improved the separation efficiency for both short and long single-stranded DNAs. ${ }^{25}$ Therefore. the mixed polymer gel system was employed in this study with the average molecular weight of Mr 8.000.000 and Mr 600.000 of PEO. A small increase of PEO gel concentration slightly increased the migration time. but did not affect much on the separation efficiency (Figure 2A and B). However a marked change on the migration time was observed when the gel concentration was further increased to $2.3 \%$ of $\mathrm{Mr}$ 8.000 .000 and $1.5 \%$ of $\mathrm{Mr} 600.000$ (Figure 2C). This could be attributed to the abrupt increase of the buffer viscosity due to the network formation between PEO chains. Note that the resolution became worse for relatively large size of the single-stranded DNA ( $>300$ bases). This means that the transient pore sizes produced by PEO chains are so small

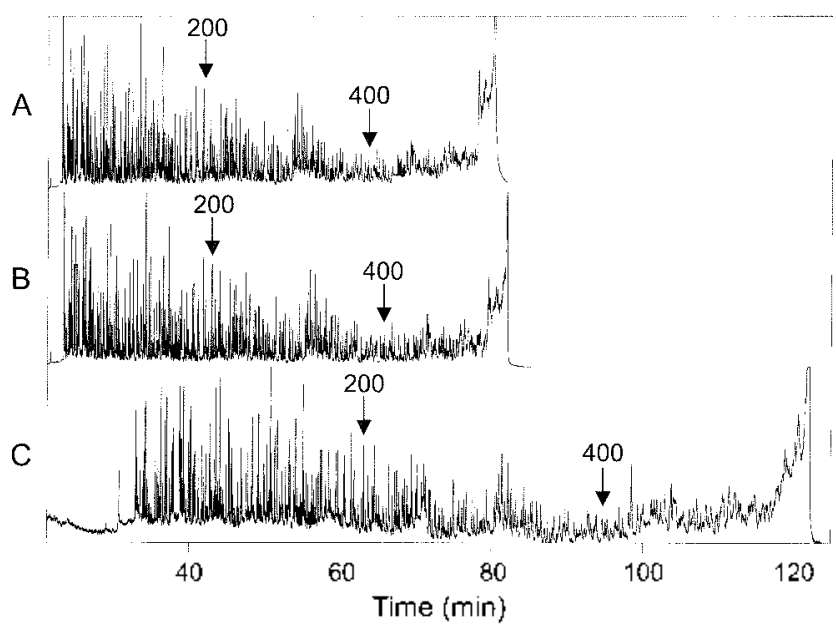

Figure 2. The electropherograms at various concentrations of PEO gel matrix. (A) $1.8 \%$ of $\mathrm{Mr} 8,000,000$ and $1.4 \%$ of $\mathrm{Mr} 600,000$, (B) $2.0 \%$ of $\mathrm{Mr} 8,000,000$ and $1.4 \%$ of $\mathrm{Mr} 600,000$, (C) $2.3 \%$ of $\mathrm{Mr}$ $8,000,000$ and $1.5 \%$ of $\mathrm{Mr} 600,000$. The electric field employed was $200 \mathrm{~V} / \mathrm{cm}$, but other conditions were the same as shown in Figure 1 .

that large DNA could not be separated with one-base resolution. We found that the mixed gel system worked well with the concentration between $1.0 \%$ and $2.0 \%$ of $\mathrm{Mr}$ 8.000 .000 and between $1.2 \%$ and $1.8 \%$ of $\mathrm{Mr} 600.000$. As long as the total concentration of mixed gel system was less than $3.1 \%$. a good resolution $(>1.2)$ was obtained. As shown in Figure 3. the mixed gel system showed good separation efficiency up to 600 bases. When the gel concentration was relatively low or only single composition of PEO was employed. information for the front end of single-stranded DNA up to 80 base was lost. Table 1 clearly shows the relationship between the separation time and DNA base information. A shorter migration time was obtained for DNA base up to $\mathbf{5 8 0}$ with single composition of PEO gel matrix. however. the mixed system made it possible to call the DNA

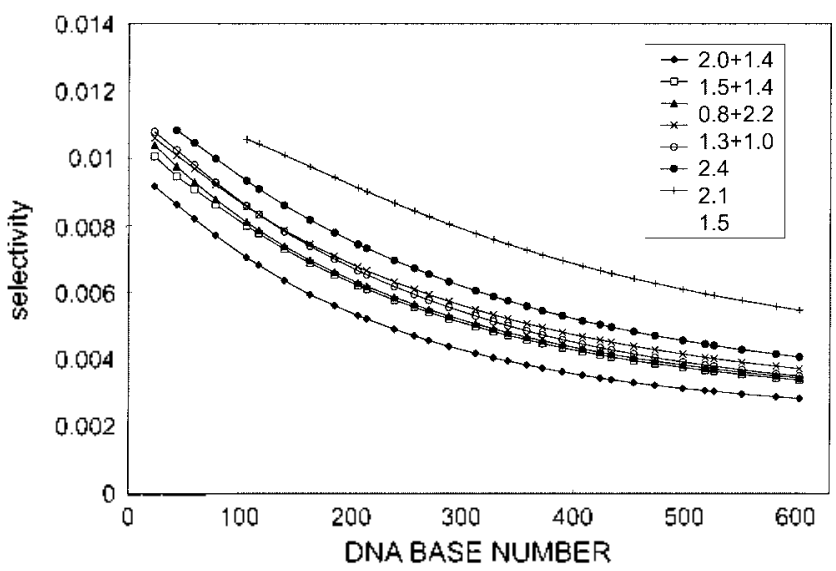

Figure 3. The mobility of single-stranded DNAs at different combinations of PEO gel matrices. The composition of gel matrix is shown in the small box and $y$-axis represents the mobility $\left(\mathrm{cm}^{2} /\right.$ Vsec j. The larger the mobility difference is, the better the separation efficiency is. The electric field employed was $150 \mathrm{~V} / \mathrm{cm}$ and other conditions were the same as shown in Figure 1. 
Table 1. DNA starting base, maxinnm read length, and the total separation tine as a function of the concentration of gel matrix (PEO)

\begin{tabular}{cccc}
\hline $\begin{array}{c}\text { PEO } \\
\begin{array}{c}\text { Concentration } \\
(\%)\end{array}\end{array}$ & $\begin{array}{c}\text { DNA } \\
\text { starting } \\
\text { base }\end{array}$ & $\begin{array}{c}\text { DNA } \\
\text { maximum read } \\
\text { length }\end{array}$ & $\begin{array}{c}\text { Separation } \\
\text { time } \\
(\text { min })\end{array}$ \\
\hline $1.5+1.4^{a}$ & 19 & 570 & 125 \\
$1.2+1.8^{b}$ & 1 & 550 & 130 \\
$1.5^{c}$ & 80 & 580 & 80
\end{tabular}

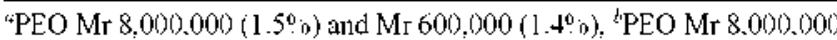
$\left(1.2^{0} \circ\right)$ and $\mathrm{Mr} 600,000\left(1.8^{0} \cdot 0\right)$, "PEO Mr $8,000,000\left(1.5^{\circ} \cdot 0\right)$.

base as low as the first one. Since DNA sequencing requires the DNA primary structure from the beginuing. it seems that $1.2 \%$ of $\mathrm{Mr} 8.000 .000$ and $1.8 \%$ of $\mathrm{Mr} 600.000$ would be the choice of $\mathrm{PEO}$ gel matrix.

It is know that the resolution in CE is not a function of capillary length when the diffusion is the main source of the band broadening ${ }^{2}$ When polyacry lamide gel was employed as the separation gel matrix high electric fields $(>300 \mathrm{~V} / \mathrm{cm})$ was suggested in order to reduce the diffusion-induced band broadening at the expense of the resolution for large $\mathrm{DNA}^{27}$ In our study, we found that the resolution improved as the capillary length increased from $25 \mathrm{~cm}$ to $100 \mathrm{~cm}$ (see the region marked by asterisk in Figure 4). Even the electric
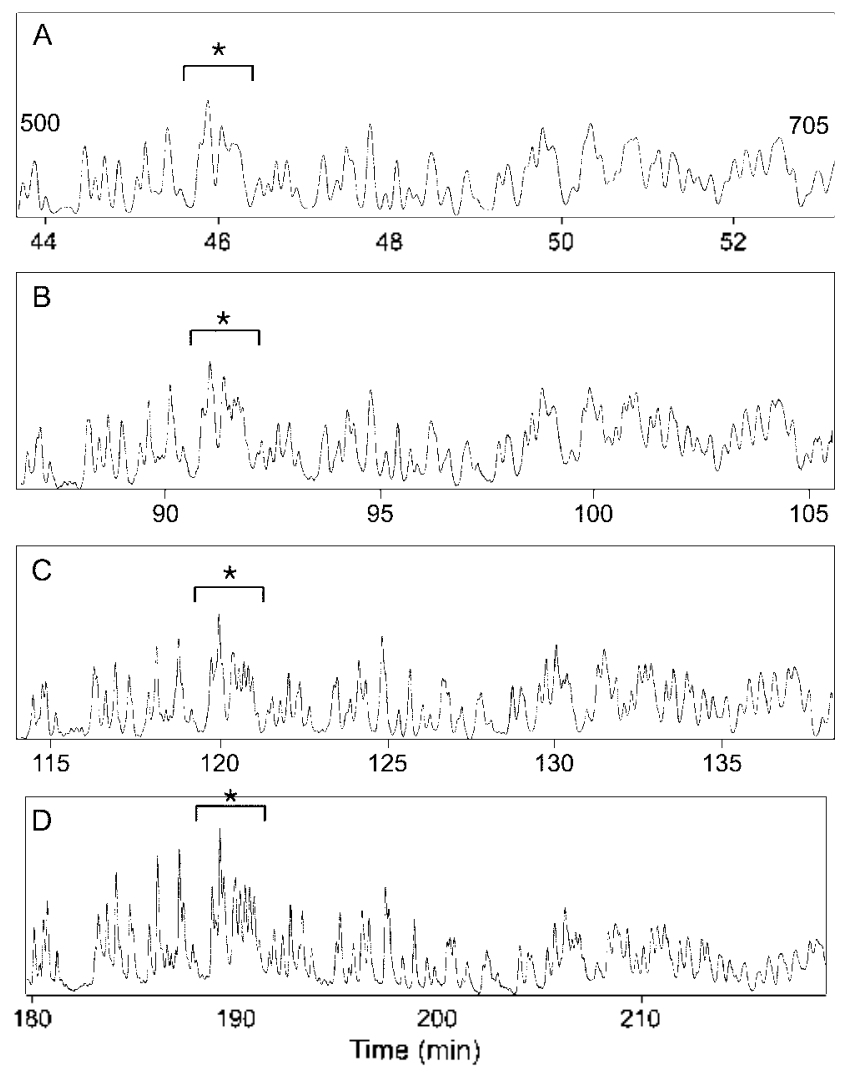

Figure 4. The electropherograms of PGEM/U standard sample. Only DNA bases between 500 base and 705 base region is shown for comparison. An effective capillary length of (A) $25 \mathrm{~cm}$, (B) 50 $\mathrm{cm}$, (C) $79 \mathrm{~cm}$, (D) $100 \mathrm{~cm}$. The G, C rich region is marked by *in order to clarify the improvement of resolution as the effective length of the capillary increased.
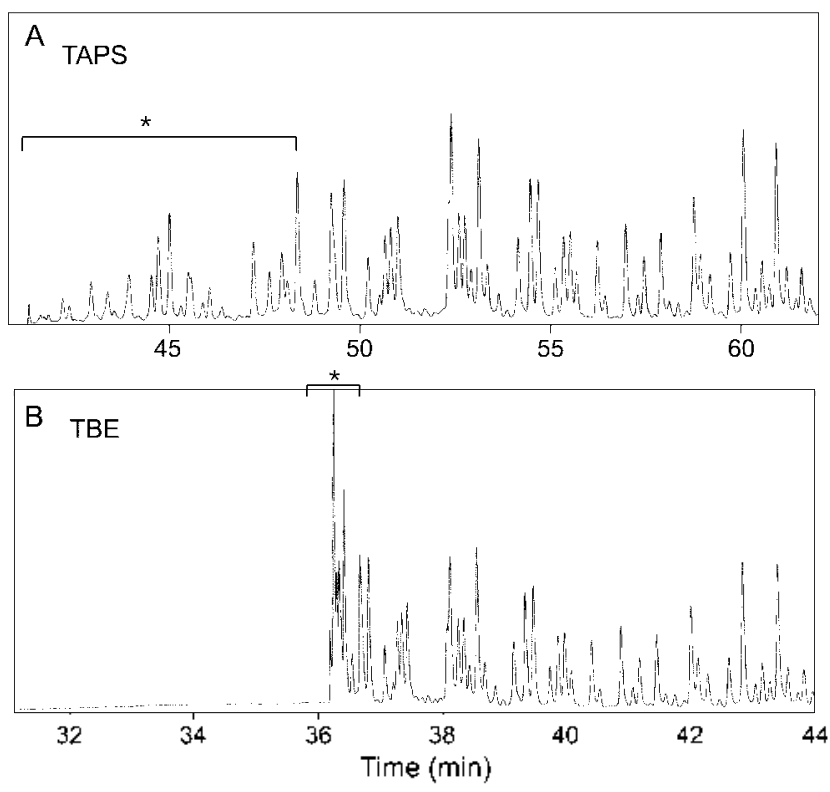

Figure 5. The number of the theoretical plates as a function of DNA base number. The effective capillary length is denoted in the figure. The number of the theoretical plates for each capillary length was normalized to $l \mathrm{~m}$ of the capilary.

field was kept at $150 \mathrm{~V} / \mathrm{cm}$ that was lower than that when polyacrylamide gel was used. ${ }^{27}$ It seems that the band broadening due to the diffusion at low electric field was not a limiting factor in our gel șystem and this could be attributed to the special pore structure and gel dynamics of $\mathrm{PEO}$. which is known to be more flexible and longer than polyacrylamide

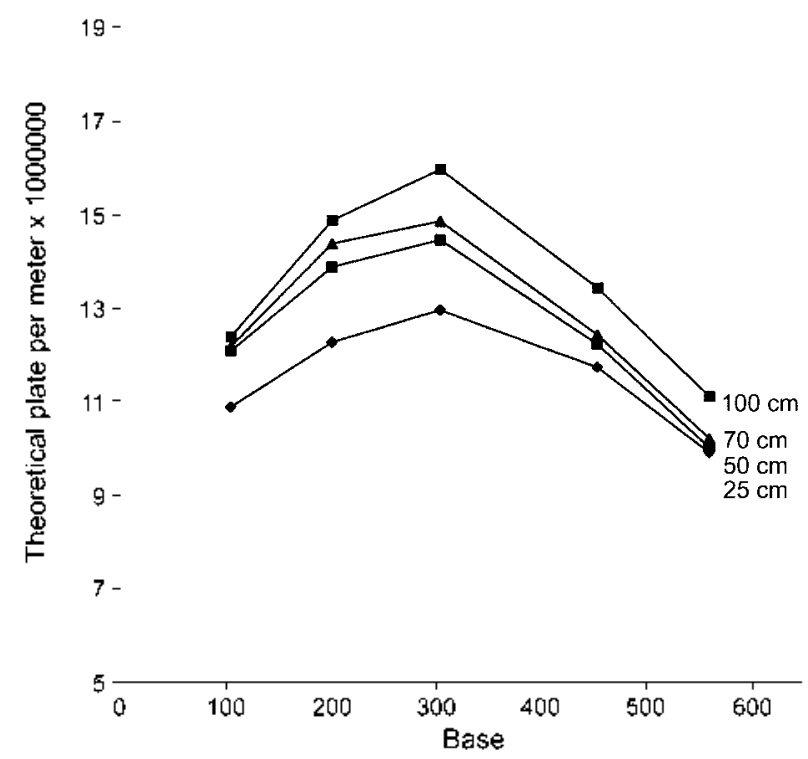

Figure 6. The electropherograms of PGEMU standard sample at different buffers. (A) TAPS ( $90 \mathrm{mM}$ TAPS and $2 \mathrm{mM}$ EDTA) buffer, (B) IX TBE buffer $90 \mathrm{mM}$ Tris, $90 \mathrm{mM}$ borate, and $2 \mathrm{mM}$ EDTA). Both buffers contained $3.5 \mathrm{M}$ urea for DNA denaturation. Other separation conditions were the same as shown in Figure l, except that the $\mathrm{PEO}$ gel was dissolved in each buffer. The region marked by *in Figure $6 \mathrm{~B}$ shows the contraction of about $30 \mathrm{DNA}$ bases. 
for the same average molecular weight. The number of the theoretical plates as a function of DNA base number was plotted in Figure 5 for each capillary length. In this case. the number of the theoretical plates for each capillary length was normalized to $1 \mathrm{~m}$ of the capillary. It is know that the maximum readable length of DNA is proportional to the square root of the capillary length. ${ }^{17}$ However, we observed that the maximum readable length of DNA reduced faster than the square root of the capillary probably due to the nature of $\mathrm{PEO}$ gel network.

It seems that the choice of the buffer is also important for the separation of single-stranded DNA. In DNA sequencing. TBE (Tris-borate-EDTA) buffer at $\mathrm{pH} 8.4$ has been commonly employed since DNA strand is very stable at this condition. We found that TAPS buffer at $\mathrm{pH} 8.4$ also provided good separation efficiency for single-stranded DNA. Especially. TAPS buffer showed a better resolution for DNA less than 30 bases (see the region marked with asterisk in Figure 6). The difference between TBE and TAPS is that acid moiety is either attached in Tris unit (sulfonic acid in TAPS) or separated (boric acid in TBE). Although it is not clear yet. one possible explanation is the complexation of borate (TBE case) and PEO chain. which can distort the network structure of PEO gel and does not provide the reasonable pore structure for relatively short DNA strands. It is well known that borate can produce complex with carbohydrate via hỵddrogen bonding ${ }^{28.25}$

\section{Conclusions}

For the research in post Genome era. DNA sequencing is still important since DNA primary structure provides the valuable information related to disease discovery. prevention of infectious disease. forensic analysis. family identification. and gene function. Therefore, the behavior of single-stranded DNA in DNA sequencing should be investigated in capillary electrophoresis that is known to provide the fast and high resolution for biomolecules. We have studied the migration behavior of single-stranded DNA using capillary gel electrophoresis under high electric field. It was found that an electric field less than $150 \mathrm{~V} / \mathrm{cm}$ should be employed for the good trade-off between the separation time and the resolution. GC rich region in DNA primary structure showed a poor resolution and the effort to improve the separation in this region is under progress. It seems that the gel matrix with the combination of polymer average molecular weight is important to extend the maximum readable DNA bases. The best result was obtained with the PEO gel concentration of $1.2 \%$ of $\mathrm{Mr} 8.000 .000$ and $1.8 \%$ of $\mathrm{Mr} 600.000$. Also. the capillary length must be carefully controlled for the balance between the total DNA migration time and the maximum readable length. We found that TBE buffer as well as TAPS buffer worked well for DNA sequencing. Especially. TAPS buffer showed a good resolution for very short DNA bases (1 to 30 bases)

Acknowledgment. This work was supported by the Kyungnam Universitỵ Research Fund 2002.

\section{References}

1. Kim. Y.: Morris, M. D. Anal Chem, 1995, 67. 784.

2. Salas-Solano, O.: Ruiz-Martinez, M. C. Lev. K. E.: Karger, B. L. And. Chem. 1998. 70. 1528.

3. Brazill. S. A.: Kim. P. H.: Kuhr. W. G. Anal Chem 2001. 73. 4882 .

4. Abuin, A.; Holt. K. H.: Platt, K. A.; Sands, A. T:- Zambrowicz. B. P. Trends in Biotechnolog: 2012, 20.36.

5. Lee, M. S.: Kerns, E. H. Hass Spectronety Review's 1999, $18,187$.

6. Zhang. Z. L.: Harrison. P. M.: Gerstein. M. Jownal of Molecular Biolog, 2002. 323.811.

7. Zhang. Y: Tan1. H: Yeung. E. S. Anal. Chem. 1999. 71.5019.

8. Nelson. R. The Lancet 2002, 360, 1667.

9. Weinberger, R.: Lurie. I. S. Anal Chen 1991, 63, 823.

10. Liu. Y; Kuhr, W. G. Andl Chem 1999, 71, 1668.

11. Studier. F. W. Trends in Biochemical Sciences 2000. 25. 588.

12. Strege. M.: Nesi. M.: Righetti. R. G. J. Chromatog. A 1993. 652. 31

13. Cohen. A. S.: Najarian, D. R; Karger. B. L. J. Chrontatog .A $1990.5] 6,49$

14. Manabe. T. Electrophonsis 1999. 20,3116.

15. Chen. H. S.: Chang. H. T. Anal Chem 1999. 71. 2033.

16. Lieberwith. U.: Arden-Jacob. T.: Drenhage. K. H.: Herten. D. P. Muller. R: Neumant1. M.: Schulz. A.: Siebert. S.: Sagner. $G ;$ Klingel, S.: Sauer, M.: Wolfrum, J. Anal Chen 1998. 70. 4772 .

17. Kim. Y: Yeung. E. S. J. Clmomatog A 1997. 781,315

18. Peck. K.: Wung. S. L.: Chang. G. S.: Yen. T. J. Y.: Hsieh. Y. Z And Chem 1997.69. 1380 .

19. Moon. B. G.: Choi. K. S.: Lee. Y. I.: Kim. Y. Afrochem. J. 2002. 72. 305 .

20. Kostrhunova. H: Brabec, V. Biochemism 20(00,39(4), 12639

21. Kim. Y. Morris, M. D. Anal. Chem 1994, 66. 3081

22. Gao. Q.: Yeung. E. S. Anal Chem. 1998. 70(7). 1382.

23. Tseng. W. L.: Chang. H. T. Electrophoresis 2001. 22. 763.

24. Rathore. A. S.: Reynolds. K. I.: Colon. L. A. Electrophoresis 2002. 23, 2918.

25. Albarghouthi. M. N.; Barron. A. E. Electrophoresis 2000. 21. 4096.

26. Harrold. M. P.: Wojtusik. M. I.: Riviello. T.: Henson. P. $J$. Chromatog. A 1993. 640.463.

27. Meada. Y.: Tsukida. N.: Kitano. H.: Terada. T.: Yamanaka. J. $J$ Phs Chem. 1993, 97. 13903

28. Takana. N.; Ito, K.; Kitano, H. Macromolecules 1994. 27. 540 